\title{
Leveraging Technology to Enhance Doctor of Nursing Practice Student Health Policy Engagement
}

\author{
Nicole Garritano, DNP, APRN, CPNP-AC \\ Melissa Stec, DNP, APRN, CNM, FACNM, FAAN
}

\begin{abstract}
Background. Doctor of nursing practice (DNP) students need to develop health policy competencies. The American Association of Colleges of Nursing formed the Faculty Policy Think Tank (FPTT) in 2015, which developed recommendations about health policy curriculum at all levels of nursing education including the DNP.

Problem. Prior to the FPTT recommendations, there were no standardized examples of health policy competencies and their evaluation.

Approach. A DNP health policy course was redesigned based on the FPTT recommendations. Technological capabilities were leveraged to provide an active and experiential learning environment integrating the concepts of cultural competence, health equity, and social awareness.
\end{abstract}

Outcomes. At the conclusion of the course, DNP students are actively engaged in health policy and have increased confidence in their advocacy abilities.

Conclusions. Providing DNP students with an experiential, technologically driven learning platform gives students practical tools and applications they can use beyond the classroom to influence health policy.

This is authors' manuscript of the work published in final form as: 
Keywords: distance learning; doctor of nursing practice (DNP); educational technology; health policy; nursing education

The current health care environment in the United States is in transition with policy and innovation colliding to meet the health demands of the American population while competing with the fiscal responsibilities of federal and state governments. Doctor of nursing practice (DNP) curricula prepare nurses to advocate for patients and innovate to improve population health outcomes. However, there have not been clearly delineated outcomes related to health policy education for nurses. The American Association of Colleges of Nursing (AACN) published the Essentials Series. ${ }^{1-3}$ There is a separate publication for each level of nursing education, each with health policy as a standalone essential with competency-based outcomes. However, there has not been consensus by AACN and academic nursing on how students can meet the specific competencies and demonstrate health policy proficiency.

In October 2015, the AACN formed the Faculty Policy Think Tank (FPTT). This group was charged with evaluating the current state of health policy education in schools of nursing around the country and developing recommendations to assist in standardizing the delivery and approach to health policy education for nursing students at all degree levels. ${ }^{4}$ Major themes from the symposium included examining health policy education through the lens of advocacy, analysis, and research. Faculty shared obstacles to health policy education, methods used to teach health policy, and trends in faculty involvement with policy. Following the symposium, the FPTT analyzed the data collected and developed recommendations. These recommendations were published in October 2017. ${ }^{4}$ 


\section{FPTT Recommendations for Academia}

Three recommendations specific to academia were developed by the FPTT. The first recommendation involves differentiating educating students who are health policy generalists versus specialists. Not all students will be health policy specialists, but all should have general health policy competencies at each degree level. Specifically, the FPTT states faculty teaching health policy should have expertise in this area and ongoing engagement. Schools should promote a culture supporting health policy practice and research that encourages faculty and students to pursue policy work. In addition to the shift in culture, there should be opportunities for both formal and informal conversations about policy for faculty and students. As a result, schools of nursing need to develop faculty with health policy expertise who will be able to mentor students with a strong interest in health policy. ${ }^{4}$

The second recommendation focuses on having a dedicated health policy leadership position within the academic infrastructure. This includes developing roles at various levels that support health policy work, allowing protected time for faculty to pursue health policy interests, promoting collaboration, and considering policy work as part of the promotion and tenure process for nursing faculty. ${ }^{4}$

The third recommendation encourages interprofessional efforts in providing health policy education. Specifically, nursing programs are encouraged to identify health policy strengths in other disciplines and departments across campuses and leverage relationships to provide the best policy education and opportunities for students. This includes highlighting nurse faculty expertise in policy education and offering joint classes for other disciplines fostering a 
collaborative dialogue, supportive structure, and clear interconnectedness of needs across disciplines. $^{4}$

\section{Course Development}

Based on feedback from the symposium along with a review of the current literature on health policy education across disciplines, and taking into consideration course delivery technology options, course redevelopment began. The DNP program where the health policy course is delivered is an Apple Distinguished iPad-based program allowing for the integration of applications and experiential assignments. The college of nursing is part of a large urban academic health center offering both a post-master's degree and BSN-DNP degree option. A blending of theoretical frameworks provided the foundation for course design along with a focus on cultural competence, health equity, and social awareness.

\section{Theoretical Frameworks}

When developing and delivering online educational offerings, it is important to consider the intersection of technology and pedagogy. Therefore, the Technological Pedagogical and Content Knowledge (TPACK) Model $^{5}$ was used to address the technology needs of the course. The theoretical framework identified specific to the development of health policy competencies and attitudes of learners about health policy was the Sessler Branden Advocacy Matrix. ${ }^{6}$

The TPACK Model focuses on content, pedagogical, and technological knowledge and examines how these 3 areas intersect and influence student learning. Content knowledge is the what or subject matter. Pedagogical knowledge includes the how or tools used to teach. Technological 
knowledge is the partner or form of technology in the course. Surrounding each of these is the context in which the students and instructor work. ${ }^{5}$

In this specific course, the content knowledge is health policy and the faculty's expertise in health policy and nursing education. The pedagogical knowledge consists of teaching and learning strategies used in the class that facilitate learning. These include group discussion, flipping the classroom, inquiry, analysis, and experiential learning and the instructor's experience using these teaching modalities. Finally, the technological knowledge determines how technology can be leveraged to add to the learning experience of students. In this course, the iPad and applications used in the class along with the instructor's familiarity and comfort using this form of technology constitute the technological knowledge. The context is a hybrid learning environment in which students have 1 class meeting during the semester and do the remaining work at a distance online.

The Sessler Branden Advocacy Matrix is a framework addressing the progression and motivation of a learner to engage in advocacy efforts. It first examines the foundational conditions, both internal and environmental, which the individual is experiencing. The internal aspects focus on the personality traits of the individual along with the current environment or situational factors. ${ }^{6}$ As an example, this educator's experience is that DNP students tend to be proactive, compassionate, and committed to the greater good. However, because of curricular requirements, students encounter situational factors including enrollment in a doctoral health policy course that places them outside their comfort zone or normal environment.

The next level of the matrix considers the conditional context of the learner. In this course, the students are presented with various institutional, community, state, federal, and global policy 
issues to consider. Once the conditional context is considered, the matrix progresses to the decision to advocate. Once the learner has decided to advocate, there are cognitive assessments that take place including identifying inequalities, inconsistencies, or discrepancies and strategizing about how to properly advocate for the desired outcome. If the need is great, and the strategy is sound, then the learner will move forward. ${ }^{6}$

Once the decision is made to advocate, the learner sets goals for facilitation, promotion, and empowerment and correctly identifies key stakeholders at the individual, group, organizational, community, national, and/or global level to engage. ${ }^{6}$ This framework provided the context for increased advocacy, analysis, and research efforts for students in the course while also allowing the instructor to create a motivational-based environment for learning about health policy.

\section{Assignment Development}

Four major assignments were developed to allow for immersive, experiential learning of advocacy, analysis, and research skills in relation to health policy. The key concepts at the core of each assignment include cultural competence, health equity, and social awareness. The 4 assignments additionally allow students to focus on health policy issues at the institutional, community, state, federal, and global levels.

\section{Cultural Competence}

The AACN has long supported the integration of cultural competence into doctoral-level nursing education programs and endorses 6 specific cultural competencies for nursing education. ${ }^{7}$ Jeffreys and Dogan's ${ }^{8}$ Cultural Competence and Confidence (CCC) Model was used as a framework in developing assignments. The CCC Model provides a multidimensional overview 
explaining how students learn cultural competence. Learning cultural competence is a cognitive, practical, and affective process in which students gain transcultural self-efficacy or confidence in providing culturally congruent care. ${ }^{8}$ While DNP level students have received cultural competence education through prior training at their place of employment and baccalaureate- and master's-level education, the CCC Model was used as a framework in designing health policy assignments that allow students to view heath policy issues through a cultural lens and grow their self-efficacy in advocating, analyzing, and researching issues from a different cultural perspective.

\section{Health Equity}

Social determinants of health and health equity are also important concepts to integrate into a doctoral-level health policy course. The Centers for Disease Control and Prevention (CDC) describe the social determinants of health as being an overlapping of complex and integrated social and economic systems that encompass social and physical environments and health services. Income, power, and resources at the global, national, and local levels impact these determinants, as well as policy and personal choices. ${ }^{9}$ As course development occurred, there was attention given to developing assignments that allowed students to contemplate the social determinants of health and reflect on how these influence health equity and the implications of health policy for health equity.

\section{Social Awareness}

Creating a sense of social awareness in students is particularly challenging in the current technology- and social media-driven world. Social awareness embodies empathy, organizational 
awareness, and service orientation and examines how people manage relationships and if they are observant of the feelings, needs, and concerns of others. ${ }^{10}$ These traits are critical in the health policy arena where one must influence, educate, and empower others. Opportunities were provided while developing the assignments for students to view issues from different perspectives and research the background of key stakeholders and other constituents.

\section{Course Structure and Assignment Overview}

The DNP health policy course is offered in a hybrid learning format with 1 on-campus meeting during the semester. During this on-campus meeting, a 3-hour class is held providing a course overview along with an interactive lecture and coaching session preparing students for the expectations throughout the semester. The course is divided into 2-week learning modules and delivered via a learning management system, iTunes $U$, and using the iPad. Each module includes readings and other learning activities including navigating health policy websites, completing online competency modules, visiting professional organization websites, posting public comments, and developing a 30-second persuasive speech on a policy issue. In addition to the biweekly modules, there are 4 assignments that allow for a more in-depth reflection on health policy issues at various levels.

\section{Video Discussion Board Assignment}

During each 2-week learning module, select students are assigned specific case studies focusing on institutional, community, and/or state health policy issues and lead their fellow classmates in a video discussion around the case study. Depending on the particular case, elements of cultural competence, health equity, and social awareness are part of the online discussions. Students use 
the camera feature on the iPad to record their responses. Responses are then uploaded to the Box app, where there are folders assigned for each module. This assignment uses group discussion, inquiry, and analysis as students discuss health policy issues. The format is very conversational and allows students to practice what is it like to engage in collegial debate and idea sharing. Many times, students have personal stories that resonate with the cases being discussed, and the conversation is passionate and thoughtful.

\section{International Policy Analysis Assignment}

Students select a health policy issue impacting another country. All issues are submitted to the instructor in advance for approval with no duplication in topics. Students create a voiceover presentation highlighting the issue of interest and the impact it has had on the country of origin. They then compare the governmental structures of the United States and the other country addressing similarities and differences. Finally, students present the pros and cons of the health policy issue along with long-term implications. This assignment encompasses cultural competence, health equity, and social awareness. Students use the Keynote app on the iPad to create their presentation and then use the recording feature launched with the release of iOS 11 to voiceover the presentation. The presentations are then uploaded to a shared folder on the Box app, where students can view each other's presentation and comment. It is evident when reviewing the presentations and comments that students are outraged over the health disparities in other countries and the oppression many governmental systems still embrace.

\section{Interprofessional Policy Assignment}


This assignment requires students to choose a health policy issue another discipline is facing and develop a mind map outlining the issue, illustrate a similar issue faced by nursing, and propose a plan for nursing and the other profession to join forces and collaborate to impact change. This assignment focuses on health equity and social awareness. Students create the mind maps using the PureFlow or iThoughts apps on the iPad. These are then converted to PDF files and uploaded to a shared folder in the Box app, where students can view each other's mind map and comment. The students often comment on one another's work incorporating what they learned through their own assignment and discussing further how the plan they each developed can be used across different interprofessional health policy issues.

\section{Advocacy in Action}

Students select an issue impacting their community or state, develop an elevator pitch supporting their views on the topic, and then schedule a meeting with their local or state representative to discuss the issue. Students then develop a video presentation highlighting the issue, the interaction and outcomes of the visit, and a personal reflection about how this experience will impact their future advocacy efforts. Students use either iMovie or Adobe Spark on the iPad to create the video presentations for this assignment. The videos are then saved as MP4 files and uploaded to a shared folder in the Box app. Students view each other's presentations and comment on the issue and visit with the representative. The component of this assignment with the most impact is the personal reflection provided by each student. Their experiences provide rich qualitative data that are enhanced because they are shared verbally reflecting the emotion, passion, and empowerment they now feel after completing this assignment.

\section{Evaluation}


Since the course has been redeveloped, it has been taught 5 semesters with 102 students. Prior to the start of each course, a survey is sent to each student to complete. The survey measures interest and readiness to participate in health policy using yes/no questions and Likert scale ratings. The same survey is sent at the completion of the course to measure changes in attitudes toward health policy. In addition, course evaluations are regularly completed at the conclusion of each course.

In reviewing the survey data cumulatively at the start of the course, $15 \%$ of the students are engaged in health policy, and at the end, 93\% self-report being involved with health policy. Seventy-five percent of the students were not a member of a professional nursing organization at the start of the course, but after the course, $80 \%$ report joining an organization. In addition, when asked on a scale of 1 to 5 how excited they were about health policy, 1 being not excited and 5 being very excited, more than $50 \%$ of the students rated themselves at a 1 or 2 prior to the course, but at the conclusion, $25 \%$ rated themselves a 1 or 2 .

In terms of advocacy, all students polled at the conclusion of the course report they would be likely to advocate for a health policy, patient, or professional issue. All but 15 students reported they felt knowledgeable about international health policy issues, which was a 50\% increase from the presurveys. The findings for knowledge about interprofessional issues were similar with a $75 \%$ increase in the knowledge base after taking the course. Most compelling is the likelihood to meet with a federal, state, or local legislator about a health policy in the future. At the beginning of the course, $10 \%$ of the students reported they would meet with a representative. However, at the conclusion of the course, $98 \%$ reported they would like to meet with a representative in the future. 
Course evaluations have been consistently positive. To date, after taking the course, there are currently 8 DNP students involved in health policy work with a professional nursing organization, 5 DNP students sitting on various boards, 1 student regularly meeting with her state representative related to advanced practice nursing full practice authority, and 1 student was named by Ohio Governor John Kasich to the state Maternal Child Health Committee. In addition, there are a number of DNP graduates now actively involved in health policy efforts.

\section{Conclusion}

As recommended by the FPTT, nursing educators need to be producing health policy generalists while planting the seeds and providing the experiences to help interested students become health policy specialists beyond graduation. The development of this DNP health policy course rooted in the TPACK Model and Sessler Branden Advocacy Matrix along with assignments influenced by the CCC Model, CDC overview of social determinants of health, and social awareness competencies has demonstrated that active, experiential learning strategies produce informed advocates - advocates capable of applying analysis and research to health policy topics while fostering social awareness, cultural competence, and an understanding of the social determinants of health. Further students learn how to use relevant applications while embracing mainstream technology. These tools are foundational to tackling health policy issues in real time and collaborating with peers while communicating with key stakeholders about important issues.

With the need for preventive, population-focused health outcomes, DNP-prepared nurses need to be fluent in health policy and competent in using the technology of today. This DNP health policy course provides a foundation for influencing lasting change that reaches beyond the classroom and into our institutions, neighborhoods, states, country, and our global communities. 
Author Affiliations: Associate Professor of Clinical Nursing (Dr Garritano) and Assistant Dean of Graduate Programs, School of Nursing, Indiana University, Indianapolis; Professor of Clinical Nursing (Dr Stec) and Associate Dean of Educational Innovation and Evaluation, College of Nursing, SUNY Downstate Medical Center, Brooklyn, New York.

N.G. was former Associate Professor of Clinical Nursing and DNP Program Director, College of Nursing, University of Cincinnati, Ohio.

The authors declare no conflicts of interest.

Correspondence: Dr Garritano, Indiana University, School of Nursing, 600 Barnhill Dr, Indianapolis, IN 46202 (nicole.garritano@icloud.com). 


\section{References}

1. American Association of Colleges of Nursing. The Essentials of Baccalaureate Education for Professional Nursing Practice. Available at http://www.aacnnursing.org/Portals/42/Publications/BaccEssentials08.pdf. Published 2008. Accessed June 3, 2018.

2. American Association of Colleges of Nursing. The Essentials of Master's Education in Nursing. Available at http://www.aacnnursing.org/Portals/42/Publications/MastersEssentials11.pdf. Published 2011. Accessed June 3, 2018.

3. American Association of Colleges of Nursing. The Essentials of Doctoral Education for Advanced Nursing Practice. Available at http://www.aacnnursing.org/Portals/42/Publications/DNPEssentials.pdf. Published 2006. Accessed June 3, 2018.

4. American Association of Colleges of Nursing. Faculty Policy Think Tank: Report and Recommendations. Available at http://www.aacnnursing.org/Portals/42/Policy/PDF/FPTTReport-10-12-2017.pdf. Published 2017. Accessed June 4, 2018.

5. Koehler MJ, Mishra P. What is technological pedagogical content knowledge? Contemp Iss Technol Teach Ed. 2009;9(1):60-70.

6. Sessler-Branden P. The Nurse as Advocate: A Grounded Theory Perspective [dissertation]. Villanova: Villanova University; 2012.

7. American Association of Colleges of Nursing. Establishing a Culturally Competent Master's and Doctorally Prepared Nursing Workforce. Available at http://www.aacnnursing.org/Portals/42/AcademicNursing/CurriculumGuidelines/Cultural- 
Competency-Grad-Edu.pdf?ver=2017-05-18-143552-087. Published 2009. Accessed June 4, 2018.

8. Jeffreys MR, Dogan E. Evaluating the influence of cultural competence education on students' transcultural self-efficacy perceptions. J Transcult Nurs. 2011;23(2):188-197.

9. Centers for Disease Control and Prevention. NCHHSTP Social Determinants of Health:

Definitions. Available at https://www.cdc.gov/nchhstp/socialdeterminants/definitions.html.

Published 2014. Accessed June 6, 2018.

10. Key Step Media. Emotional and Social Leadership Competencies: An Overview. Available at https://www.keystepmedia.com/emotional-social-intelligence-leadership-competencies/.

Published 2017. Accessed June 6, 2018. 